\title{
Avaliação de atividade inflamatória na osteomielite crônica. Contribuição da cintilografia com anticorpos policlonais.
}

\author{
M.T. Sapienza, F. Hironaka, A.L.L.M. Lima, L.Y.I Yamaga, E. Hamada, T. Watanabe, P.A. Costa, C.A. \\ BUCHPIGUEL
}

Trabal ho realizado no Centro de Medicina Nuclear do Departamento de Radiol ogia da Faculdade de Medicina da Universidade de São Paulo, São Paulo, SP.

\begin{abstract}
RESUMO - Овj etivo. O diagnóstico de osteomielite crônica em atividade ou sobreposta a outras patologias é difícil, pois estas situações mascaram os achados radiológicos de infecção. A especificidade da cintilografia do esqueleto ou com gálio-67 também é reduzida pela influência da remodelação óssea na captação destes radiofármacos. Anticorpos policlonais marcados com tecnécio-99m (Tc-99m-IgG) apresentam captação independente do metabolismo ósseo, sendo um dos radiofármacos em investigação para avaliação mais específica de infecção.
\end{abstract}

Casuística e Método. Neste estudo comparou-se a cintilografia com Tc-99m-IgG, cintilografia óssea trifásica e cintilografia com gálio-67 no diag-

\section{NTRODUÇÃO}

A confirmação diagnóstica de osteomielite crônica em atividade pode indicar a necessidade de antibioticoterapia prolongada ou intervenção cirúrgica. O quadro clínico-radiológico, entretanto, nem sempre é conclusivo ${ }^{1}$. A radiografia simples é muito empregada pela sua disponibilidade, baixo custo e por fazer o diagnóstico diferencial com outras patologias. Contudo, apresenta baixa especificidade para osteomielite em pacientes com alterações ósseas prévias², 3 .

Os métodos cintilográficos auxiliam no diagnóstico da osteomi elite por permitirem a detecção das alterações funcionais presentes neste processo infeccioso. A cintilografia óssea com difosfonatos marcados com tecnécio-99m mostra aumento de remodelação óssea na área infectada e sua alta sensibilidade, inclusive em uma fase precoce, a torna o método de el eição no diagnóstico de osteomielite aguda em pacientes sem doença óssea prévia e com osso radiologicamente normal. Entretanto o aumento de remodelação e hipercaptação dos difosfonatos ocorre em diversas patologias, sendo um achado pouco específico. Nestes casos a cintilografia óssea é muitas vezes complementada pela cintilografia com gálio-67, marcador inflama- nóstico da osteomielite crônica em atividade em 23 segmentos ósseos; correlacionando-as com dados clínico-laboratoriais e radiológicos.

Resultados. Oito dos 23 segmentos for am classificados como infectados, 11 não infectados e quatro inconclusivos. A sensibilidade e especificidade encontradas para cintilografia óssea, com gálio-67 e com Tc-99m-IgG foram, respectivamente, 88 e $36 \%$, 75 e $73 \%$, 88 e $82 \%$.

Conclusão. Os resultados sugerem que a TC99m-IgG possa ser utilizada no diagnóstico da osteomielite crônica em atividade.

UNITERMOS: Cintilografia. Osteomielite. Anticorpos.

tório, cuja captação poderia confirmar a presença de osteomi elite. Porém a concentração de gálio-67 é, em parte, dependente da atividade osteometabólica e ocorre em locais de remodelação óssea, mesmo na ausência de infecção, reduzindo sua especificidade.

E m 1988 foi descrita a detecção cintil ográfica de abscessos em ratos, causados por Pseudomonas aeruginosa, após a administração de anticorpos monoclonais não específicos para o agente etiológico ${ }^{4}$. Nos anos seguintes verificou-se que os anti corpos policlonais marcados com índio- $111^{5}$ ou tecnécio- $99 \mathrm{~m}^{6}$ são também captados por processos inflamatórios. Os mecanismos de captação dos anticorpos policlonais no foco inflamatório não estão bem estabelecidos. Não parece haver influência da remodel ação óssea na captação, o que nos fez supor que a cintilografia com anticorpos policlonais pudesse ser mais específica que a cintilografia óssea ou com gálio-67 na investigação de osteomi elite, em especial nos casos com alterações seqüelares ou outras patologias associadas.

No presente trabalho procurou-se avaliar a cintilografia com anticorpos policlonais marcados com tecnécio-99m e compará-la com a cintilografia óssea e com gálio-67 no diagnóstico de atividade infecciosa na osteomielite crônica. 


\section{CASUÍSTICA E MÉTOdOS}

Entre 1994 e 1995 foram estudados 23 segmentos ósseos em 20 pacientes de 15 a 81 anos de idade (média $=37$ ), sendo 11 do sexo masculino e nove do sexo feminino. Os pacientes foram encaminhados pelo ambulatório do Instituto de Ortopedia do Hospital das Clíni cas da F acul dade de M edicina da Universidade de São Paulo. Todos os pacientes apresentavam al terações osteoarticulares prévias e foram investigados quanto a presença de osteomielite crônica em atividade infecciosa.

A avaliação e o seguimento dos pacientes foram obtidos por período não inferior a seis meses. Ao lado da avaliação clínica foi feita análise de dados radiológicos e laboratoriais; incluindo leucograma, velocidade de hemossedimentação e estudos bacteriológicos. O quadro clínico-laboratorial e radiológico era conhecido pelo infectologista, que acompanhava os pacientes no ambulatório de ortopedia.

\section{Critérios para a determinação de infecção em atividade}

Os casos foram classificados utilizando-se os seguintes critérios: história e apresentação clínica; evolução clínico-cirúrgica e resposta à antibioticoterapia (quando realizada); dados laboratoriais; achados radiológicos. As manifestações e sinais clínicos mais valorizados foram fístulas ativas; sinais flogísticos locais e manifestações infecciosas sistêmicas. A vel ocidade de hemossedimentação aumentada, leucocitose e culturas positivas sugeriram o diagnóstico laboratorial de infecção. Os principais achados radiológicos valorizados foram a modificação do padrão em relação aos exames anteriores e a presença de seqüestros. Com base nestes critéri os os pacientes foram separados nos grupos $A$ (sem infecção) e $B$ (infecção comprovada ou com alta probabilidade).

\section{Marcação dos anticorpos policlonais}

Os anticorpos foram preparados no Instituto de Pesquisa Energéticas e Nucleares (IPEN) para marcação direta, baseada na redução de pontes dissúlfidicas para formação de grupos sulfidrila, com alta afinidade pelo tecnécio-99m7. Resumidamente, a imunoglobulina humana (Sandoglobulina - Sandoz) foi incubada com 2-mercaptoetanol e purificada por gel-filtração em Sephadex. A cada $1 \mathrm{mg}$ de anticorpo reduzido, adicionou-se metilenodifosfonato, cloreto estanhoso e ácido paraaminobenzói co, precedendo a marcação com tecnéci o-99m. A eficiência de marcação observada por cromatografia em papel foi acima de $90 \%$ aos 10 minutos e estável por até 24 horas.
Cintilografia: As cintilografias foram realizadas no Centro de Medicina Nuclear da Universidade de São Paulo (LIM-43), em câmara de cintilação modelo Orbiter (Siemens Medical Systems), com registro analógi co e digital das imagens. Para cada paciente os três estudos foram concluídos no máximo em três semanas.

Cintilografia óssea: As imagens foram adquiridas em pelo menos duas incidências da área suspeita, com 300 a 500 kcontagens, duas horas após a administração endovenosa de 740 a 1110 M Bq de 99mT c-metilenodifosfonato (MDP), preparado no Centro de Medicina Nuclear (LIM-44).

Cintilografia com gáli o-67: I magens foram adquiridas 48 horas após a administração endovenosa de $111 \mathrm{MBq}$ de gálio-67 (citrato de gálio IPEN), na melhor incidência para identificação da área suspeita, com 300 kcontagens ou 10 minutos de duração.

Cintilografia com anticorpos policlonais: I magens em duas incidências da área de interesse foram adquiridas 4 e 24 horas após a administração endovenosa de 555 a $740 \mathrm{MBq}$ de ${ }^{99 \mathrm{~m} T c \text { canti- }}$ corpos policlonais (IgG - IPEN), com 300 kcontagens (imagens de 4 horas) ou 100 kcontagens (imagens de 24 horas).

Análise das cintilografias: As imagens da cintilografia óssea, com gálio-67 e anticorpos policl onais em 4 e 24 horas, foram analisadas por dois médicos nucleares, sem outras informações do paciente, descrevendo-se a presença e grau (discreto, moderado ou acentuado) da hipercaptação do radi ofármaco. A graduação foi estabelecida por critérios subjetivos, incluindo a comparação da região com as estruturas contralaterais, a radiação de fundo e as estruturas de biodistribuição normal. Os estudos cintilográficos com hipercaptação focal moderada ou acentuada do traçador foram considerados positivos. As imagens com captação normal ou aumentada em grau discreto foram consideradas negativas. A captação aumentada em grau discreto foi considerada negativa já que a observação prévia dos autores sugeria ser este padrão o mais freqüente nos pacientes sem infecção mas com antecedentes de trauma ou cirurgia. N os casos com hi percaptação de gálio, comparou-se o grau e a extensão da alteração com a observada na cintilografia óssea.

Para análise semi-quantitativa foram definidas regiões de interesse sobre a área suspeita nas imagens da cintilografia óssea, reproduzidas de forma especular sobre as estruturas contra-laterais e posteriormente copiadas para os demais estudos. Calculou-se um índice semi-quantitativo 
$(R)$, dividindo-se o valor de contagens na área suspeita sobre a contra-lateral. Níveis de corte que permitissem a melhor separação dos pacientes com e sem infecção foram definidos para cada método cintilográfico.

Com base na análise visual e semi-quantitativa foram calculadas a sensibilidade, a especificidade, valores de predição e acurácia de cada método. Os métodos cintilográfi cos foram comparados entre si em tabelas $2 \times 2$ e a distribuição dos resultados discordantes foi avaliada empregando-se o cál culo por distribuição binomial.

\section{RESULTADOS}

Foram estudados 23 segmentos ósseos em 20 pacientes. Excluíram-se da análise quatro segmentos considerados inconclusivos quanto a presença de infecção, prosseguindo-se o estudo com 19 segmentos em 18 pacientes. Em 11 pacientes os segmentos analisados foram negativos para infecção (grupo A). Quatro destes pacientes não tinham suspeita atual ou prévia de osteomi elite, apresentando ferimento por arma de fogo em um e antecedente de cirurgia ósteo-articular não complicada em três casos. Os sete restantes apresentavam antecedentes infecciosos sem suspeita de atividade na época ou seis meses prévios ao estudo. $\mathrm{Na}$ época do exame não havia seqüestros ou piora do padrão radiológico, alterações da velocidade de hemossedimentação ou leucograma sugestivos de infecção. Os pacientes foram acompanhados sem tratamento clínico ou cirúrgico e mantiveram-se sem manifestações de infecção por no mínimo seis meses após o estudo.

Oito segmentos em sete pacientes apresentavam osteomi elite em atividade (grupo B). Quatro pacientes apresentavam fratura exposta entre 2 e 7 anos, concomitante à infecção femoral em um paciente (osteossíntese de fratura femoral com evolução para pseudoartrose há 7 anos). Em três destes quatro pacientes foi isolado Staphylococcus aureus na cultura de secreção de fístula, associado a Flavimonas oryzihabitans em um caso. A quinta paciente apresentava osteomielite hematogênica em tíbia há seis semanas, isolando-se Serratia marcencis na cultura por punção óssea; o sexto paciente apresentava osteomielite crônica de cabeça femoral há 34 anos com secreção purulenta (cultura positiva para Streptococcus viridans) e o sétimo apresentava pioartrite de quadril há sete meses. Todos os pacientes com infecção apresentavam sinais flogísticos acentuados há mais de um mês e a velocidade de hemossedimentação média era de $28 \mathrm{~mm}$ (normal em um paciente e al terada nos demais). O leucograma foi normal em quatro pacientes e apresentou discreta leucocitose sem desvio em três pacientes. Após a cintilografia, os pacientes receberam antibioticoterapia e três foram submeti dos à limpeza cirúrgica, todos cursando com mel hora do quadro clínico.

Análise visual: A cintilografia óssea foi positiva em sete dos 11 segmentos sem infecção (grupo A) e em sete dos oito com infecção (grupo B). A sensibilidade e especificidade foram de $88 \%$ e $36 \%$, valores preditivos positivo e negativo de $50 \%$ e $80 \%$ e acurácia de $58 \%$. Se a hipercaptação discreta do traçador fosse considerada indicativa de infecção, a sensibilidade e especificidade seriam de $88 \%$ e $0 \%$. I magens de fluxo e equilíbrio foram obtidas em 9 pacientes do grupo $A$ e sete pacientes do grupo $B$, com discreta hiperemia nos nove e aumento de fluxo em dois pacientes do grupo A e hiperfluxo e hiperemia em grau variável nos sete pacientes do grupo B.

A cintilografia com gálio- 67 foi positiva em três segmentos sem infecção e seis com infecção, com $75 \%$ de sensibilidade, $73 \%$ de especificidade, $67 \%$ de val or preditivo positivo, $80 \%$ de valor preditivo negativo e $74 \%$ de acurácia. Valorizando-se a hipercaptação discreta, a sensibilidade e especificidade seriam de $88 \%$ e $9 \%$. E $m$ apenas um paciente o grau de captação de gáli o-67 foi mai or que o de Tc-99m-MDP (sens. 12\%, esp. 100\%).

A cintilografia com anticorpos policlonais foi positiva em dois casos do grupo $A$ e sete do grupo B. A sensibilidade e especificidade foram de $88 \%$ e $82 \%$, valor preditivo positivo e negativo de $78 \%$ e $90 \%$, acurácia de $84 \%$. Considerando-se os casos de hipercaptação discreta como positivos, a sensibilidade e especificidade seriam de $88 \%$ e $36 \%$.

Os resultados dos métodos cintilográficos foram comparados dois a dois, e a análi se por distribuição binomial não demonstrou discordância significativa entre os resultados ( $p>0,05)$.

\section{Análise semi-quantitativa}

A relação de contagens da área suspeita sobre a área contra-lateral $(R)$ foi calculada em 10 pacientes do grupo A e sete pacientes do grupo B, de forma separada na cintilografia óssea, com gálio67 e com anticorpos marcados. Os val ores médios de $R$ nos grupo A e $B$ foram: cintilografia óssea $=2,26$ e 3,31; cintilografia com gálio=1,26 e 1,31; cintilografia com anticorpos policlonais em 4 horas $=1,24$ e 1,57 e 24 horas $=1,25$ e 1,46. Os níveis de corte escolhidos foram: 1,94 para cintilografia óssea, 1,17 para a cintilografia com gáli o-67, 1,34 para a cintilografia com anticorpos em 4 horas e 1,28 em 24 horas; resultando em sensibilidade de 


\begin{tabular}{|c|c|c|c|c|c|c|c|}
\hline \multirow[t]{2}{*}{ Grupo A } & \multicolumn{3}{|c|}{ Cintilografia } & \multirow[t]{2}{*}{ Grupo B } & \multicolumn{3}{|c|}{ Cintilografia } \\
\hline & óssea & gálio & $\overline{\lg G}$ & & óssea & gálio & $\lg G$ \\
\hline$A C$ & ++ & ++ & ++ & AS' & ++ & ++ & ++ \\
\hline EB & + & + & + & CS & +++ & ++ & ++ \\
\hline EF & ++ & + & - & $\mathrm{Cl}$ & ++ & ++ & ++ \\
\hline IS & + & + & + & $\mathrm{Cl}^{\prime}$ & ++ & ++ & ++ \\
\hline IS' & +++ & ++ & ++ & GS & ++ & ++ & ++ \\
\hline KJ & +++ & + & + & MP & - & + & ++ \\
\hline MS & +++ & + & + & MM & +++ & ++ & ++ \\
\hline RO & ++ & ++ & + & $A L$ & ++ & - & - \\
\hline $\mathrm{RB}$ & ++ & + & - & & & & \\
\hline ZS & + & + & - & & & & \\
\hline AS & + & - & - & & & & \\
\hline
\end{tabular}

$86 \%$ para os anticorpos policlonais em 4 horas e $71 \%$ para os demais métodos. A especificidade foi de $70 \%$ para a cintil ografia óssea, $50 \%$ para o gálio$67,80 \%$ para os anticorpos policlonais em 4 horas e $70 \%$ em 24 horas. A relação de contagens aumentou entre 4 e 24 horas após a administração do anticorpo policlonal em cinco casos do grupo A e dois do grupo B (sens. $29 \%$, esp. $50 \%$ ). Apenas dois pacientes com osteomielite em atividade apresentaram maior relação com gálio-67 do que na cintilografia óssea.

\section{DISCUSSÃO}

O diagnóstico de osteomielite crônica em atividade ou superposta a outras patologias é difícil, assim como o próprio conceito de cura, podendo ocorrer prolongados intervalos assintomáticos. A confirmação bacteriológica da infecção é considerada ideal, porém não foi possível em parte dos pacientes estudados. Critérios clínico-radiológicos também podem ser empregados, em especial nos pacientes com baixa probabilidade de infecção, evitando procedimentos invasivos e por vezes inconclusivos, tendo em vista a dificuldade na definição do local mais adequado para investigação.

A especificidade da avaliação radiológica para osteomielite é reduzida na presença de alterações prévias do osso. Relata-se sensibilidade de $55 \%$ a $60 \%$ e especificidade próxima a $70 \%$ para osteomielite subaguda ou crônica ${ }^{8}$ pela radiologia convencional. Mesmo na ausência de sinais inflamatórios, os seqüestros são consi derados evidência de osteomielite em atividade, já que a reagudização pode ocorrer pela proliferação de bactérias abrigadas em tecidos desvitalizados ${ }^{1,3}$. Em 104 pacientes com suspeita de osteomielite superposta a trauma ou infecção prévia, a alter ação radiológica mais específica foi a presença de seqüestros, com sensibilidade de apenas $9 \%$. A presença de erosão, edema de partes moles ou reação periosteal mostrou sensibilidade e especificidade de 51 e $80 \%^{2}$. A tomografia computadorizada, além do diagnóstico, é indicada para avaliação da extensão e monitoração de procedimentos invasivos. Entretanto, também pode ser difícil a diferenciação entre manifestações de osteomielite crônica ou alterações seqüelares ósseas por este método ${ }^{3}$. Apesar da maior sensibilidade na detecção de seqüestros, descreve-se até $20 \%$ de resultados falso- positivos pela tomografia quando correlacionada a achados cirúrgi $\cos ^{2,3}$. A pesar da alta sensibilidade e especificidade, próximas a $95 \%$ e $88 \%{ }^{9}$, o el evado custo dificulta a aplicação rotineira da ressonância magnética. A presença de implantes metálicos causa artefatos e dificul ta a interpretação da tomografia e da ressonância magnética.

A avaliação cintilográfica de osteomielite baseia-se nas alterações funcionais decorrentes da infecção e sofre menor influência das alterações anatômicas. Muitos radiofármacos são empregados no diagnóstico da osteomielite, não estando ainda definido o método de escolha para osteomielite crônica associada à alterações anatômicoradiológicas. Na osteomielite aguda com RX normal emprega-se usualmente a cintilografia óssea, sugerindo-se o uso do estudo com leucócitos marcados na osteomielite aguda com RX alterado ${ }^{10} \mathrm{e}$ do gálio-67 na osteomielite vertebral ${ }^{11}$.

A captação dos difosfonatos na cintilografia óssea se faz principalmente por adsorção à superfície de cristais no componente mineral ósseo, caracterizando-se a osteomielite por aumento de remodelação, e conseqüente hipercaptação do radiofármaco. Na presença de alterações radiológicas, a cintilografia óssea é indicada pelo seu alto valor preditivo negativo, tendo pouco val or quando positiva. Em 983 pacientes apresentou sensibilidade de $88 \%$ e especificidade de $92 \%$ para osteomiel ite aguda, porém em 800 pacientes com outras patologias associadas, a especificidade caiu para $34 \%$ (sens. 93\%) ${ }^{12}$. Em 547 pacientes com suspeita de reativação de osteomielite crônica a cintilografia óssea teve sensibilidade de $100 \%$ e especificidade de $0 \% 12$.

O gálio-67 liga-se à transferrina após sua administração endovenosa. Múltiplos fatores parecem estar envolvidos, porém a captação inflamatória se faz predominantemente por exsudação do compl exo gálio-67-transferrina na área com aumento de fluxo e permeabilidade vascular, podendo ocorrer posterior fixação a leucócitos ou proteínas do infiltrado inflamatório e mesmo a componentes bacterianos. 

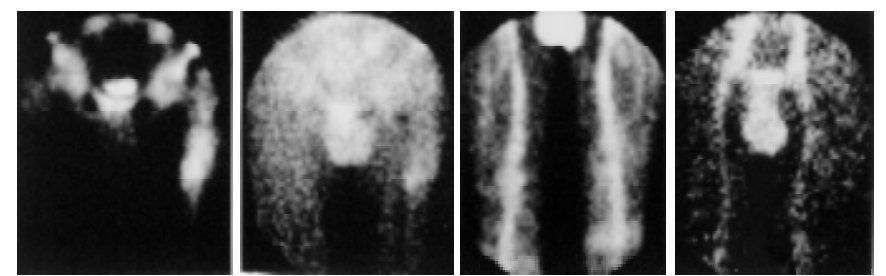

Fig. 1 - Osteomielite crônica sequelar. Paciente com deformidade e esclorose de fêmur esquerdo. Cintilografia óssea e com gálio-67 falso-positivas (A e B). Cintilografia com anticorpos policlonais negativa (hipercaptação discreta) em 4 e 24 h (C e D).
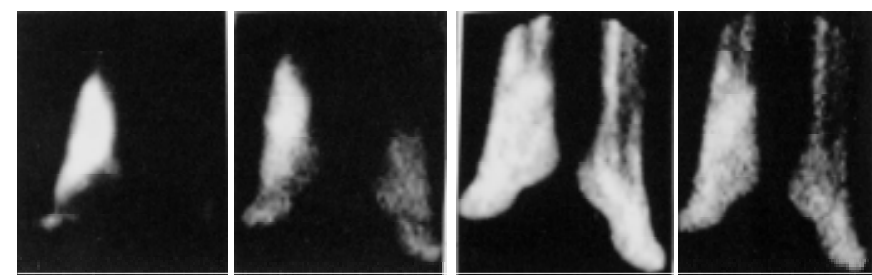

Fig. 2 - Osteomi el ite crônica em ati vidade. Paciente com fratura e osteossíntese de tíbia/ tálus D. Os três estudos foram positivos: ci ntilografia óssea (A), com gálio-67 (B) e com anticorpos policlonais com 4 e 24 h (C e D).

Parte da captação do gálio-67 é proporcional ao aumento da remodelação óssea, talvez por troca iônica na fase mineral óssea. A sensibilidade e especificidade do gálio-67 para osteomielite foram de $81 \%$ e $69 \%$ em 529 pacientes, com menor especificidade (0 a 25\%) na avaliação de osteomielite associada a outras patologias ${ }^{9,13}$. Na osteomielite crônica em atividade, estes valores foram de $75 \%$ e 82\% (227 pacientes) ${ }^{12}$. A maior captação de gáli o-67 em comparação a dos compostos difosfonatos indica predomínio da captação inflamatória sobre a remodelação. Tal fato constitui um achado muito específico de osteomielite, porém é observado em apenas $24 \%$ a $28 \%$ dos casos $^{2,13}$. Em nosso estudo apenas $12 \%$ dos segmentos com infecção apresentaram captação do gálio-67 superior à do MDP-Tc99m. Apesar de suas limitações quanto a especificidade, resolução espacial e dose de radiação, o gálio-67 continua como a melhor opção para complementar a cintilografia óssea na investigação de osteomielite do esquel eto axial, situação em que os outros métodos são bastante limitados ${ }^{12}$.

A cintilografia com anticorpos policlonais marcados com índio-111 foi introduzida clinicamente no final da década de $80^{5}$, iniciando-se em 1990 o uso de anticorpos marcados com tecnécio- $99 \mathrm{~m}^{6}$. Os anticorpos policlonais podem ser captados por mecanismos inespecíficos tais como aumento de fluxo sangüíneo, permeabilidade capilar e espaço intersticial provocados pelos mediadores inflamatórios. O extravasamento protéico isoladamente não explica a maior concentração de anticorpos que de outras proteínas de menor peso mole- cular ${ }^{14}$, havendo talvez contribuição de características específicas da molécula do anticorpo. A ligação a receptores $\mathrm{F}$ c leucocitários foi um dos primeiros mecanismos propostos, porém é atualmente pouco valorizada, devido à localização extra-celular do anticorpo marcado, a não variação na captação após degl icosilação da porção F c e ausência de bloqueio competitivo com anticorpos não marcados $^{15}$. Outros mecani smos propostos são a ligação às bactérias (proteína A), pol imerização das moléculas de anticorpos, interação de cargas elétricas e a desmarcação do anticorpo com fixação do isótopo livre ou sob outras formas radioquímicas ${ }^{15,16}$.

No presente trabalho, os anticorpos policlonais foram marcados com tecnécio-99m pela técnica de marcação direta com "kit" de preparo instantâneo e alta efi ciência de marcação ${ }^{7}$. Além do bai xo custo e alta disponibilidade, o tecnécio-99m tem como vantagens suas características físicas ideais para obtenção de i magens em câmaras de cintilação com baixa dose de radiação para o paciente (meia vida de 6 horas, radiação gama com $140 \mathrm{keV}$ ). A cintilografia com anticorpos policlonais marcados com índio-111 apresentou sensibilidade de $94 \%$ e especificidade de $89 \%$ para processos inflamatórios osteoarticulares em revisão de 393 pacientes ${ }^{12}$. Quando empregados anticorpos marcados com tecnéci o-99m, a sensibilidade varia de 71 a 95\% e especificidade de 81 a 100\% (média de $88 \%$ e $83 \%$ em 128 pacientes) $)^{6,17,18}$. A sensibilidade dos anticorpos marcados com índio-111 para processos crônicos varia de 86 a $100 \%{ }^{19}$, sendo relatada sensibilidade de $71 \%$ em estudo com anticorpos marcados com tecnécio- $99 \mathrm{~m}^{17}$. O acúmulo mais lento dos anticorpos nos processos crônicos pode ser a explicação para os melhores resultados obtidos com marcação com índio-111 do que com tecnécio-99m, pois as características de decaimento e clareamento sangüíneo do primeiro possibilita a aquisição de imagens tardias.

No presente estudo, a sensibilidade encontrada pel os três métodos foi semel hante. A pesar de não ser constatado discordância estatisticamente significativa, os resultados sugerem que a especificidade da cintilografia com anticorpos policlonais seja superior a da cintil ografia com gáli io-67 e ambas superiores a da cintilografia óssea. A especificidade foi calculada em população de indi víduos com patologias osteoarticulares não infecciosas, provavelmente sendo maior em população sem acometimento ósseo prévio. De forma geral, não houve ganho de sensibilidade e especificidade da análise semiquantitativa em relação à visual. A cintilografia óssea foi o único método com ganho de especificidade, podendo indicar que pacientes com diferentes graus de hipercaptação 
tenham sido agrupados visualmente nas mesmas categorias. O valor médio encontrado para o índice semiquantitativo de captação de I gG neste estudo foi de 1,57 em 4 horas e 1,46 em 24 horas, similar ao descrito em estudo com 17 pacientes com osteomielite crônica ${ }^{17}$.

O único resul tado falso negativo da cintilografia óssea foi encontrado na paciente com pioartrite de quadril e osteomielite femoral, e cultura de secreção positiva para Streptococcus viridans. Talvez uma menor captação do radiofármaco tenha ocorrido devido à acentuada lise da cabeça femoral constatada radiologicamente. Esta paciente também apresentou gálio-67 falso-negativo e cintilografia com anticorpos policlonais positiva. Outro paciente, submetido à osteossíntese de fratura exposta de tálus com cultura de secreção positiva para Staphylococcus aureus, apresentou cintilografia com gálio-67 e com anticorpos policlonais falso-negativos e cintilografia óssea positiva. Os resultados falso-positivos da cintilografia óssea devem estar relacionados ao aumento de remodelação óssea por causas não infecciosas, o que também pode ter contribuído para os três estudosfalso positivos com gálio-67. Os dois resultados falso-positivos na cintilografia com anticorpos policlonais e os três da cintilografia com gálio-67 podem estar relacionados a processos inflamatórios não infecciosos (decorrentes do trauma / cirurgia). A osteossíntese pode levar a inflamação asséptica pelo próprio trauma cirúrgico, irritação mecânica por mobili dade entre impl antes e tecidos vizinhos ou por reação eletrolítica do metal com tecidos orgâni $\cos ^{20}$. As principais causas descritas de estudos falso-positivos com anticorpos policlonais são os processos inflamatórios estéreis (fraturas, hematomas, sinovite, artrite, tumores), sendo menos freqüentes os estudos falso-negativos, geralmente relacionados a processos crônicos, em baixo grau de atividade ou associada à vasculopatias.

A dose equivalente de radiação absorvida por um adul to em cintilografia com $370 \mathrm{MBq}$ de anticorpos policlonais-Tc-99m é de 2,9 mSv, inferior a da cintilografia óssea (4,4 mSv) e gálio-67 (12,2 mSv) ${ }^{21}$. Não são descritas reações adver sas à administração de anticorpos policlonais em doses diagnósticas ${ }^{15}$, e não há desenvol vimento de anticorpos anti-murínicos por ser uma proteína de origem humana. Quanto a disponibilidade, o gálio-67 é produzido por ciclotron, sendo distribuído semanalmente, com meia-vida de 78 horas, enquanto o metilenodifosfonato e os anticorpos policlonais podem ser liofilizados e armazenados, sendo marcados com tecnécio-99m no momento de sua utili- zação. Considerando-se o material e tempo de utilização da câmara, a cintilografia com anticorpos policl onais deve ter um custo intermediário entre a cintilografia óssea e com gáli o-67.

\section{CONCLUSÕES}

A pesar da sensibilidade semelhante, as cintilografias com anticorpos policl onais e gálio-67 tiveram maior especificidade do que a cintilografia óssea. A maior disponibilidade, menor custo e menor dose de radiação com o uso dos anticorpos policlonais marcados sugere a indicação dos mesmos como complementação à cinti lografia óssea no diagnóstico da atividade infecciosa em osteomielite crônica ou associada a outras al terações ósseas.

\section{SUMMARY}

\section{Scintigraphic evaluation of chronic osteo- myelitis with technetium-99m labeled poly- clonal immunoglobulin}

BACKGROUND. Active chronic osteomyelitis or complicating osteomyel itis are difficult to be diagnosed by radiological imaging modalities, such as plain radiograph and CT. They frequently cause increased bone remodeling, leading to nonspecific uptake of Tc-99m-bone scan agents and gallium67. N ew radiopharmaceuticals with greater infection avidity are being developed, including the nonspecific polyclonal immunoglobulin (IgG) labeled with technetium-99m. Tc-99m-IgG may be available as a ready to use kit, with no reported side effects, low patient absorbed radiation dose and low cost. Material and Methods: 23 bone segments with suspected active chronic osteomye litis or violated bone osteomyelitis were studied by Tc-99m-I gG scintigraphy. All patients underwent standard three-phase bone scintigraphy using methyl ene di phosphonate (Tc-99m-MDP), gallium67 scintigraphy and plain radiographs, compared with clinical evaluation and laboratory tests values. Results: Infection was found in 8 sites. Sensitivity and specificity for Tc-99m-MDP, gallium-67 and Tc-99m-IgG scintigraphy were, respectively, 88 and $36 \%, 75$ and $73 \%, 88$ and $82 \%$. Conclusion: Tc-99m-IgG may be usefull in the scintigraphic evaluation of osteomyelitis. [Rev. Ass Med Bras 2000; 46(2): 106-12]

KEY WORDS: Scintigraphy. Osteomyelitis. Antibody.

\section{REFERÊNCIAS BIBLIOGRÁFICAS}

1. Resnick D, Niwayama G. Osteomyelitis, septic arthritis, and 
soft tissue infection: mechanisms and situations. In: Resnock D, Niwayama G eds. Diagnosis of boneand joint disorders, 3 ed. Philadel phia, Saunders, 1995; 2325-418.

2. Tumeh, A P, et al. Disease activity in osteomyelitis: role of scintigraphy. Radiology 1987; 165: 781-4.

3. Tumeh SS et al. Chronic osteomyelitis: the relative roles of scintigrams, plain radiographs and transmission computed tomography. Clin Nucl Med 1988; 13: 710-5.

4. Rubin RH, Young LS, Hansen $P$ et al. Specific and nonspecific imaging of localized Fisher immunotype 1 Pseudomonas aeruginosa infection with radiolabeled monoclonal antibody. J Nucl Med 1988; 29: 651-6.

5. Fischman AJ, Rubin RH, Khaw BA et al. Detection of acute inflammation with ${ }^{111} \mathrm{I}$-labeled nonspecific polyclonal IgG. Semin Nucl Med 1988; 18: 335-44.

6. Buscombe J R, Lui D, Ensing G, J ong R, EII PJ . ${ }^{99 m} T$ c-human immunoglobulin (HIG) - first results of a new agent for the localization of infection and inflammation. Eur J Nucl Med 1990; 16: 649-55.

7. Mather S, Ellison D. Reduction-mediated technetium-99m labeling of monoclonal antibodies. J Nucl Med 1990; 31: 692-7.

8. Al-Sheikh W, Sfakianakis GN, Mnaymneh W et al. Subacute and chronic bone infections: diagnosis using In-111, Ga-67 and Tc-99m MDP bone scintigraphy and radiography. Radiology 1985; 155: 501-6.

9. Schauwecker DS. The scintigraphic diagnosis of osteomyelitis. A J R 1992; 158: 9-18.

10. Datz FL. Indium111-labeled leukocytes for the detection of infection: current status. Semin Nucl Med 1994; 24:92-109.

11. Palestro CJ. The current status of gallium imaging in infection. Semin Nucl Med 1994; 24:128-41.
12. Elgazzar AH, Abdel-Dayem HM, Clark J D, Maxon HR. Multimodality imaging of osteomyelitis. Eur J Nucl Med 1995; 22:1043-63.

13. Schauwecker DS, Park HM, Mock BH et al. Evaluation of complicating osteomyelitis with Tc99m MDP, In111 granulocytes, and Ga67 citrate. J Nucl Med 1984; 25: 849-53.

14. Ercan M, Ünlenen E. Accumulation of some small molecular weight complexes of ${ }^{99 m} \mathrm{Tc}$ in experimental abscesses. Nucl Med Biol 1994; 21: 143-9.

15. Rubin RH, Fischman AJ . The use of radiolabeled nonspecific immunogl obulin in the detection of focal inflammation. Semin Nucl Med 1994; 24: 169-79.

16. Claessens RAMJ, Koenders EB, Oyen WJ G, Abrams MJ, Solomon HF, Corstens FHM. Release of technetium from TC99m-I gG in infectious foci. J Nucl Med 1994; 35: 45.

17. Sciuk J, Brandau W, Vollet B et al. Comparison of technetium99m polyclonal human immunoglobulin and technetium-99m monocl onal antibodies for imaging chronic osteomyelitis. Eur J Nucl Med 1991; 18: 401-7.

18. Hotze AL, Briele $B$, Rieker $O$, Overbeck $B$, Biersack $H J$. Detection of bone and joint inflammation with Tc-99m human unspecificimmunoglobulin (HIG). J Nucl Med 1992; 33: 839-40.

19. Oyen WJ G, van Horn J R, Claessens RAMJ , SlooffTJ J H, van der Meer J WM, Corstens FHM. Diagnosis of bone, joint and joint prosthesis infections with In-111-labeled nonspecific human immunoglobulin G scintigraphy. Radiology 1992; 182: 195-9.

20. Pavón SJ . I mplantes metálicos en ortopedia y traumatologia. 1 ed. Buenos Aires, Ed Médica Panamericana, 1975.

21. Saptogino A, Becker W, Wolf F. Biokinetics and estimation of dose from ${ }^{99 m}$ Tc-labelled polyclonal human immunoglobulin (HIG). J Nucl. Med 1991; 30: 18-23. 